\title{
El leísmo en el español paraguayo
}

\author{
O leísmo no espanhol paraguaio
}

\author{
Sebastian Stanley ${ }^{*}$ \\ Universidade Federal daBabia \\ Salvador, Bahia, Brasil \\ CarlosFelipe da ConceiçãoPinto** \\ Universidade Federal daBabia \\ Salvador, Bahia, Brasil
}

\begin{abstract}
Resumen: Describimos y analizamos aquí el fenómeno del leísmo paraguayo confrontando los datos e hipótesis de Herreros (1976), Granda (1982), Palacios (2000) y Symeonidis (2013). El objetivo general es verificar el estado del fenómeno del leísmo paraguayo. El marco teórico es sociolingüístico-histórico y gramatical-morfosintáctico descriptivo. Confrontamos hipótesis sobre el fenómeno del leísmo peninsular y del leísmo paraguayo y la variación lingüística en contextos sócio-históricos como la aislación periférica, el contacto entre lenguas y el peso normativo de centros culturales de influencia. Los resultados indican una alternancia de le como única forma pronominal con lo, además de una significativa presencia de la y las en los sociolectos más altos y con mayor grado de escolarización.
\end{abstract}

Palabrasclave:Variación lingüística. Variedades del español. Español paraguayo. Leísmo en Paraguay.

Resumo: Descrevemos e analisamos aqui o fenômeno do leísmo paraguaio confrontando os dados e hipóteses de Herreros (1976), Granda (1982), Palacios (2000) e Symeonidis (2013). O objetivo geral é verificar o estado do fenômeno do leísmo paraguaio. O marco teórico é sociolinguístico-histórico e gramatical-morfossintático e descritivo. Confrontamos hipóteses sobre o fenômeno do leísmo peninsular e do leísmo paraguaio e a variação linguística em contextos sócio-históricos como o isolamento periférico, o contato entre línguas e o peso normativo de centros culturais de influência. Os resultados indicam uma alternância de le como única forma pronominal com $l o$, além de uma significativa presença de la e las nos socioletos mais altos e com maior grau de escolarização.

Palavras-chave:Variação linguística; Variedades do Espanhol; Espanhol paraguaio; Leísmo no Paraguai.

\section{INTRODUCCIÓN}

En este artículo vamos a analizar el fenómeno del leísmo en la variedad del español paraguayo comparando el sistema pronominal átono de tercera persona de ésta variedad

*Doutorando do Programa de Pós-Graduação em Língua e Cultura - PPGLinC - Universidade Federal daBabia, Salvador, Bahia, Brasil. E-mail: ibantobscuri@gmail.com.

** Professor do Programa de Pós-Graduação em Língua e Cultura - PPGLinC - Universidade Federal daBabia, Salvador, Bahia, Brasil. E-mail: cfpinto@ufba.br. 
con el sistema pronominal átono estándar, representado en la Tabla 1. En esta aproximación al fenómeno nos vamos a limitar a confrontar y analizar diferentes datos e hipótesis sobre el leísmo peninsular y sobre el leísmo paraguayo en particular así como sobre la variación lingüística en contextos sócio-históricos determinados como la aislación periférica y el contacto entre lenguas, con el fin de corroborar si el fenómeno del leísmo en el español paraguayo se extiende aún hoy según lo descripto por Granda (1982).

Tabla 1: Sistema pronominal átono y tónico de objeto estándar ${ }^{1}$

\begin{tabular}{|c|c|c|c|c|c|c|c|}
\hline \multicolumn{4}{|c|}{ Acusativo } & \multicolumn{4}{|c|}{ Dativo } \\
\hline & Latín & \multicolumn{2}{|c|}{ Español } & & Latín & \multicolumn{2}{|c|}{ Español } \\
\hline $1 \mathrm{~s}$ & $\mathrm{ME}$ & $\begin{array}{l}\text { me } \\
\text { a mí }\end{array}$ & $\begin{array}{l}\text { Me vio a } \\
\text { mí }\end{array}$ & 1s & MIHI & $\begin{array}{l}\text { me } \\
\text { a mí }\end{array}$ & $\begin{array}{l}\text { Me dio el } \\
\text { lápiz a mí }\end{array}$ \\
\hline $2 \mathrm{~s}$ & TE & $\begin{array}{l}\text { te } \\
\text { a ti }\end{array}$ & Te vio a ti & $2 \mathrm{~s}$ & TIBI & $\begin{array}{l}\text { te } \\
\text { a ti }\end{array}$ & $\begin{array}{l}\text { Te dio el } \\
\text { lápiz a ti }\end{array}$ \\
\hline $\begin{array}{l}3 \mathrm{~s} \\
\mathrm{~m} \\
3 \mathrm{sf}\end{array}$ & $\begin{array}{l}\text { ILLUM/I } \\
\text { LLUD } \\
\text { ILLAM } \\
\text { (ILLE/IL } \\
\text { LA) }{ }^{2}\end{array}$ & $\begin{array}{l}\text { lo } \\
\text { la } \\
\text { a él/ella }\end{array}$ & $\begin{array}{l}\text { Lo vio a él } \\
\text { La vio a } \\
\text { ella }\end{array}$ & $3 \mathrm{~s}$ & ILLI & $\begin{array}{l}\text { le } \\
\text { se } \\
\text { a él/ella }\end{array}$ & $\begin{array}{l}\text { Le dio el } \\
\text { lápiz a } \\
\text { él/ella } \\
\text { Se lo dio a } \\
\text { él/ella }\end{array}$ \\
\hline $1 p$ & NOS & $\begin{array}{l}\text { nos } \\
\text { a } \\
\text { nosotros/ } \\
\text {-as }\end{array}$ & $\begin{array}{l}\text { Nos vio a } \\
\text { nosotros / } \\
\text {-as }\end{array}$ & $1 p$ & & $\begin{array}{l}\text { nos } \\
\text { a } \\
\text { nosotros/ } \\
\text {-as }\end{array}$ & $\begin{array}{l}\text { Nos dio el } \\
\text { lápiz a } \\
\text { nosotros/ } \\
\text {-as }\end{array}$ \\
\hline $2 \mathrm{p}$ & VOS & $\begin{array}{l}\text { Os } \\
\text { a } \\
\text { vosotros/- } \\
\text { as }\end{array}$ & $\begin{array}{l}\text { Os vio a } \\
\text { vosotros / } \\
\text {-as }\end{array}$ & $2 \mathrm{p}$ & & $\begin{array}{l}\text { Os } \\
\text { a } \\
\text { vosotros/- } \\
\text { as }\end{array}$ & $\begin{array}{l}\text { Os dio el } \\
\text { lápiz a } \\
\text { vosotros/ } \\
\text {-as }\end{array}$ \\
\hline $\begin{array}{l}3 \mathrm{p} \\
\mathrm{m} \\
3 \mathrm{pf}\end{array}$ & $\begin{array}{l}\text { ILLOS } \\
\text { ILLAS }\end{array}$ & $\begin{array}{l}\text { los } \\
\text { las } \\
\text { a } \\
\text { ellos/ellas }\end{array}$ & $\begin{array}{l}\text { Los vio a } \\
\text { ellos } \\
\text { Las vio a } \\
\text { ellas }\end{array}$ & $3 p$ & ILLIS & $\begin{array}{l}\text { les } \\
\text { se } \\
\text { a } \\
\text { ellos/ellas }\end{array}$ & $\begin{array}{l}\text { Les dio el } \\
\text { lápiz a } \\
\text { ellos/ellas } \\
\text { Se lo dio a } \\
\text { ellos/ellas }\end{array}$ \\
\hline
\end{tabular}

En español existen usos de los pronombres átonos de tercera persona en los que la selección del pronombre no está determinada por la posición o función sintáctica del antecedente, casos que tradicionalmente se denominan leísmo, laísmo y loísmo. En la gramática descriptiva RAE (1999) se entiende por leísmo el uso de le, pronombre átono de tercera persona singular de dativo, en lugar de lo, pronombre átono de tercera persona singular masculino de acusativo, como pronombre para referirse a un complemento u objeto directo singular masculino de persona, y en menor grado a un complemento u

${ }^{1}$ Datos obtenidos de la Real Academia Española (RAE) (1999 y 2009).

${ }^{2}$ Del nominativo. 
objeto directo singular masculino de cosa. El leísmo plural es menos frecuente que los anteriores y más frecuente si referido a persona que a cosa. Excepcionalmente el leísmo ocurre en lugar de la, pronombre átono de tercera persona singular femenino de acusativo, como pronombre para referirse a un complemento u objeto directo singular femenino y de persona, y muy raramente en plural, como representado en la Tabla 2. No hay referencia a leísmo cuando el referente es neutro.

Tabla 2: Sistema pronominal átono leísta más generalizado según RAE (1999)

\begin{tabular}{|l|l|l|l|l|l|}
\hline \multicolumn{3}{|c|}{ Acusativo } & \multicolumn{3}{l|}{ Dativo } \\
\hline $3 \mathrm{sm}$ & le & $\begin{array}{l}\text { Le vio a él }+++++ \\
\text { Le vio al barco }++++ \\
\text { ee vio a ella }+++ \\
\text { La vio a la casa }\end{array}$ & $3 \mathrm{~s}$ & $\begin{array}{l}\text { le } \\
\text { se }\end{array}$ & $\begin{array}{l}\text { Le dio el lápiz a él/ella } \\
\text { Se lo dio a él/ella }\end{array}$ \\
\hline $3 \mathrm{pm}$ & la & $\begin{array}{l}\text { Les vio a ellos }+++ \\
\text { Les vio a los barcos }++ \\
\text { Les vio a ellas }+ \\
\text { Las vio a las casas }\end{array}$ & $3 \mathrm{p}$ & $\begin{array}{l}\text { les } \\
\text { se }\end{array}$ & $\begin{array}{l}\text { Les dio el lápiz a ellos/ellas } \\
\text { Se lo dio a ellos/ellas }\end{array}$ \\
\hline
\end{tabular}

Según Granda (1982) una de las peculiaridades más significativas de la baja estandarización del español paraguayo está claramente representada por el sistema pronominal átono de tercera persona, en el que se produjo una situación de leísmo extremamente particular, donde la forma le es empleada, además de como objeto indirecto singular y plural referida a sustantivos masculinos, femeninos y neutros, también como objeto directo singular y plural, masculino y femenino, como se puede apreciar en la Tabla 3.

Tabla 3: Sistema pronominal átono leísta paraguayo según Granda (1982)

\begin{tabular}{|c|c|c|c|c|c|}
\hline \multicolumn{3}{|r|}{ Acusativo } & \multicolumn{3}{|r|}{ Dativo } \\
\hline $\begin{array}{l}3 \\
s\end{array}$ & le & $\begin{array}{l}\text { Le vio a él } \\
\text { Y entonce mi primo me recordó que su mamá o } \\
\text { sea mi tía é también mi maína y tengo que } \\
\text { pascuar por ella... y entonce, a la do de la } \\
\text { mañana me subí en el caballo y me juí a la casa y } \\
\text { a la do y media por ahí llegué y le deperté para } \\
\text { pascuarle y ella me abrazó } \\
\text {...y tiene todo su torre iluminada pero cuando } \\
\text { yo le ví parece que no é tan alta como vo eperá } \\
\text {...un billete medio viejo ya, pero no etaba roto. } \\
\text { Masiado bien me acuerdo que saqué y le puse ahí }\end{array}$ & $3 \mathrm{~s}$ & le & $\begin{array}{l}\text { Le dio el lápiz a } \\
\text { él/ella }\end{array}$ \\
\hline
\end{tabular}

3 (APPLEYARD, 1973, p. 99 apud GRANDA, 1982, p. 263).

4 (APPLEYARD, 1973, p. 40 apud GRANDA, 1982, p. 263).

5 (APPLEYARD, 1973, p. 77 apud GRANDA, 1982, p. 263). 


\begin{tabular}{|l|l|l|l|l|l|}
\hline 3 & $l e$ & Le vio a ellos/ellas/cosas $\mathrm{m} / \mathrm{f}$ & 3 & le & $\begin{array}{l}\text { Le dio el lápiz a } \\
\text { ellos/ellas }\end{array}$ \\
\hline
\end{tabular}

Granda (1982) sostiene que el leísmo paraguayo no se da, contra lo que exponen Kany (1969) y Herreros (1976), solamente cuando se refiere a persona, a diferencia del leísmo peninsular europeo y americano, en el que ésta es la característica principal del fenómeno. Granda (1982) sostiene que el leísmo paraguayo se extiende además a la designación de cosa tanto en singular como en plural y en masculino, femenino o neutro, empleándose en todos los casos la forma le. Se trata, en resumen, de un leísmo individualizado por dos rasgos esenciales: su absoluta generalidad, abarcando referentes ( \pm humano) ( \pm animado) ( \pm masculino) ( \pm singular), y su invariabilidad formal, ya que el morfema le funciona en el español paraguayo como única forma de objeto directo e indirecto para la totalidad de los casos posibles sintácticamente, independientemente del género, el número y la caracterización semántica del sustantivo al que es referido.

Según Granda (1982), desde el punto de vista diatópico no hay diferencias en el empleo de la forma le como objeto directo e indirecto en ninguna zona del país, y desde el punto de vista diastrático el leísmo paraguayo se encuentra en los isolectos más distanciados de la norma lingüística regional en la totalidad de sus registros orales y escritos y en los isolectos medios y superiores en los registros orales fundamentalmente, aunque también se dan casos en el registro escrito, y en circunstancias preferentemente no formales, si bien, en ocasiones normales, se pueden encontrar también casos de leísmo, sobre todo referidos a sustantivos caracterizados por las notas ( + humano) ( + animado) ( + singular) independientemente del sexo y edad de los hablantes. Sin embargo, Granda (1982) proporciona sólo cuatro ejemplos pertenecientes a la lengua escrita literaria que extrajó de Appleyard (1973).

Palacios (2000) refiere que cuando el referente es ( + humano) ( + masculino) $( \pm$ singular) y (+ humano) (- masculino) $(+$ singular $)$ el objeto directo es pronominalizado mediante la forma le y que cuando el referente es ( + humano) (- masculino) (- singular) la pronominalización del objeto directo se realiza mediante la forma de acusativo la $(s)$. No encuentra en el corpus ejemplos de objetos pronominalizados mediante le con referentes (- masculino) (- singular) y refiere que sus informantes paraguayos universitarios le confirmaron que la norma local no admite "*le veo a las niñas sino las veo a las niñas" (PALACIOS, 2000, p. 128). Cuando el referente es (- humano) (- animado) ( \pm masculino) refiere que la pronominalización del objeto directo se efectúa mediante la forma le, de manera similar a lo que ocurre en las variedades de español de Ecuador y del País Vasco, pero los ejemplos que da en este último caso los retoma de Granda (1982) ya que refiere haber encontrado solo dos y que tal dificultad obedece a la generalización de la elisión de objeto (- animado). Afirma haber detectado también la coexistencia de un fenómeno de loísmo entendido como la aparición del pronombre lo como forma única para referirse a objetos cuyos referentes son ( \pm masculino) ( \pm singular), y un sólo caso de ( + humano) (masculino) (- singular), y que dicho fenómeno no ha sido mencionado en la bibliografía especializada. También refiere la existencia de elisión del pronombre átono de tercera persona de acusativo singular masculino y femenino como un fenómeno ampliamente 


\section{Revista}

\section{das Letras}

generalizado y documentado tanto en la lengua hablada como en la escrita, pero los ejemplos que da fueron extraídos de la novela Hijo de hombre de Roa Bastos (1989), como puede apreciarse en la Tabla 4.

Tabla 4: Sistema pronominal átono leísta paraguayo según Palacios (2000)

\begin{tabular}{|c|c|c|c|c|c|}
\hline \multicolumn{3}{|r|}{ Acusativo } & \multicolumn{3}{|c|}{ Dativo } \\
\hline $3 \mathrm{~s}$ & $\begin{array}{l}\text { lo } \\
\text { la/lo } \\
\text { le }\end{array}$ & 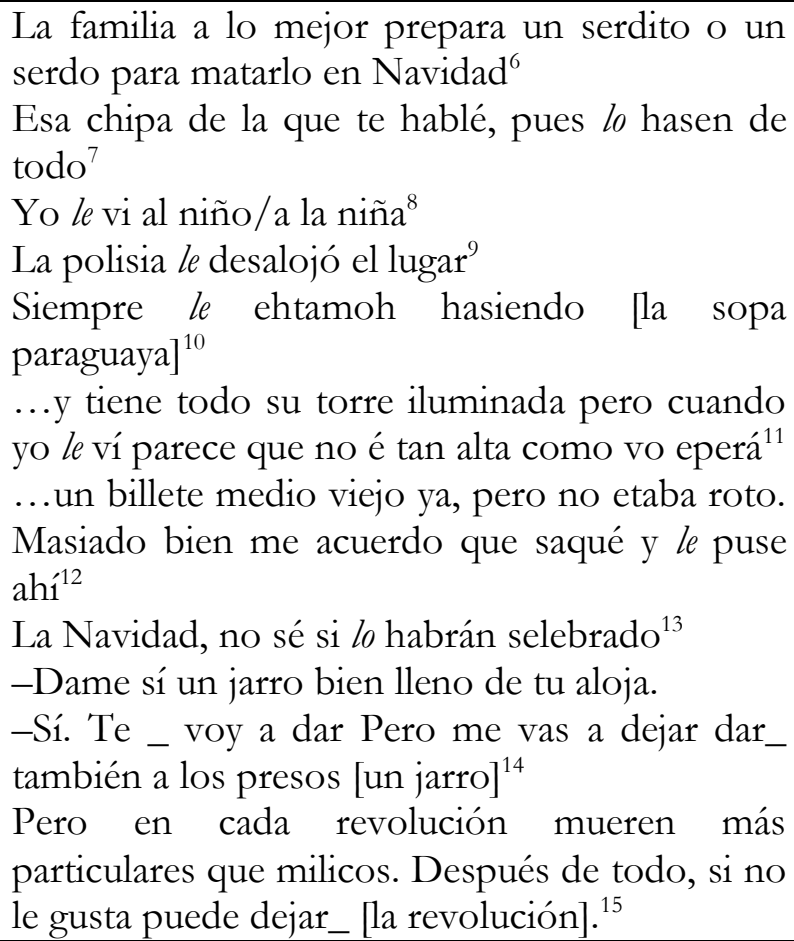 & $3 \mathrm{~s}$ & le & $\begin{array}{l}\text { Le dio el } \\
\text { lápiz a } \\
\text { él/ella }\end{array}$ \\
\hline $3 p$ & $\begin{array}{l}\text { le } \\
\text { la/las } \\
\text { lo }\end{array}$ & $\begin{array}{l}\text { Yo le vio a los niños }{ }^{16} \\
\text { Yo la }(\mathrm{s}) \text { vi a las niñas }\end{array}$ & $3 p$ & le & $\begin{array}{l}\text { Le dio el } \\
\text { lápiz a }\end{array}$ \\
\hline
\end{tabular}

${ }^{6}$ (PALACIOS, 2000, p. 130). Hay varios casos como éste encontrados en zona rural de sociolecto mediobajo que Palacios (2000) clasifica como de loísmo pero que en realidad se corresponden con el uso estándar, como veremos más adelante.

7 (PALACIOS, 2000, p. 131) Aquí vemos una alternancia entre la y lo dentro de la misma oración referida al mismo objeto directo esa chipa.

8 (PALACIOS, 2000, p. 123).

9 (PALACIOS, 2000, p. 128).

${ }^{10}$ (PALACIOS, 2000, p. 128).

11 (APPLEYARD, 1973, p. 40 apud GRANDA, 1982, p. 263, apud PALACIOS, 2000, p. 123).

12 (APPLEYARD, 1973, p. 77 apud GRANDA, 1982, p. 263, apud PALACIOS, 2000, p. 124).

13 (PALACIOS, 2000, p. 124).

14 (BASTOS, 1989, p. 216 apud PALACIOS, 2000, p. 124).

15 (BASTOS, 1989, p. 92 apud PALACIOS, 2000, p. 124).

16 (PALACIOS, 2000, p. 123).

${ }^{17}$ (PALACIOS, 2000, p. 123). 


\begin{tabular}{|l|l|l|l|}
\hline & $\begin{array}{l}\text { Hay comunidadeh indígenah porque ahora el } \\
\text { gobierno lo } \text { cuida }^{18} \\
\text { Aqllí hay muchísimoh animaleh en el monte, } \\
\text { muchísimoh, entonse elloh van a cazar porque } \\
\text { sabe que en un día o en dos } l o \text { matan }^{19}\end{array}$ & ellos/ella \\
\hline
\end{tabular}

Desde el punto de vista diatópico y diastrático afirma que el leísmo de persona está muy generalizado, excepto en los objetos cuyos referentes son (- masculino) (- singular), y que dicho leísmo afecta a todos los sociolectos, pero parece predominar en los sociolectos medio y medio altos, generalmente con instrucción universitaria, así como parece predominar en la población urbana, a diferencia de la población rural, que utiliza el loísmo, y que esta generalización del leísmo no anula el uso de otras formas pronominales minoritarias.

Palacios (2000) trabaja con un corpus heterogéneo extraído principalmente de encuestas y grabaciones directas de hablantes paraguayos bilingües guaraní-español (de ambos sexos, de edades entre los 25 y 45 años, de zonas rurales y urbanas de Asunción, con distinto estatus sociocultural e instrucción primaria, secundaria y universitaria) y datos de la lengua escrita extraídos de otros estudios de naturaleza gramatical así como de textos literarios.

Symeonidis (2013) refiere que en el leísmo del español paraguayo se emplea como única forma el pronombre personal de tercera persona le para referentes tanto ( \pm singular), y que en los pocos casos en que se utilizan los pronombres estándar de acusativo ocurre solamente en la clase alta ${ }^{20}$, como se puede apreciar en la Tabla 5.

Tabla 5: Sistema pronominal átono leísta paraguayo según Symeonidis (2013)

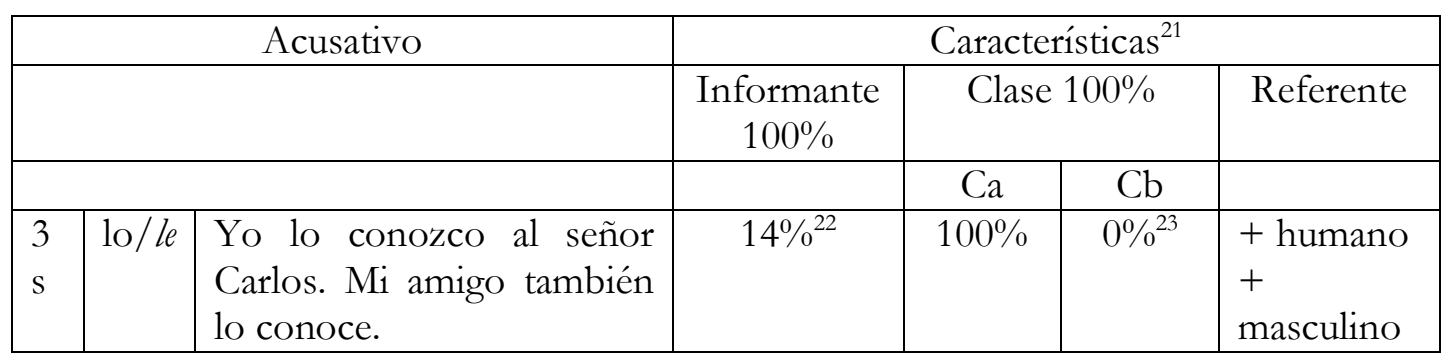

18 (PALACIOS, 2000, p. 124).

${ }_{19}$ (PALACIOS, 2000, p. 130).

${ }^{20}$ Que en su investigación se refiere a: bilingües con entre 5 y 8 años de escolarización.

${ }^{21}$ Descarto la característica diageneracional porque Symeonidis (2013) no utiliza un único sistema de referencia por cada grupo referencial, lo que dificulta enormemente cargar los datos en una única tabla con un único sistema de referencia.

${ }^{22}$ No discrimina todas las posibilidades sobre el 100\%: debe entenderse como que el $94 \%$ usó la forma le y el $14 \%$ la forma lo en cualquiera de las combinaciones posibles: lo/lo, le/lo, lo/le y donde las formas combinadas lo/ le y le/ lo están también contabilizadas dentro del $94 \%$ de le.

${ }^{23}$ Se entiende sobre el $14 \%$ que usó la forma $l o$. 


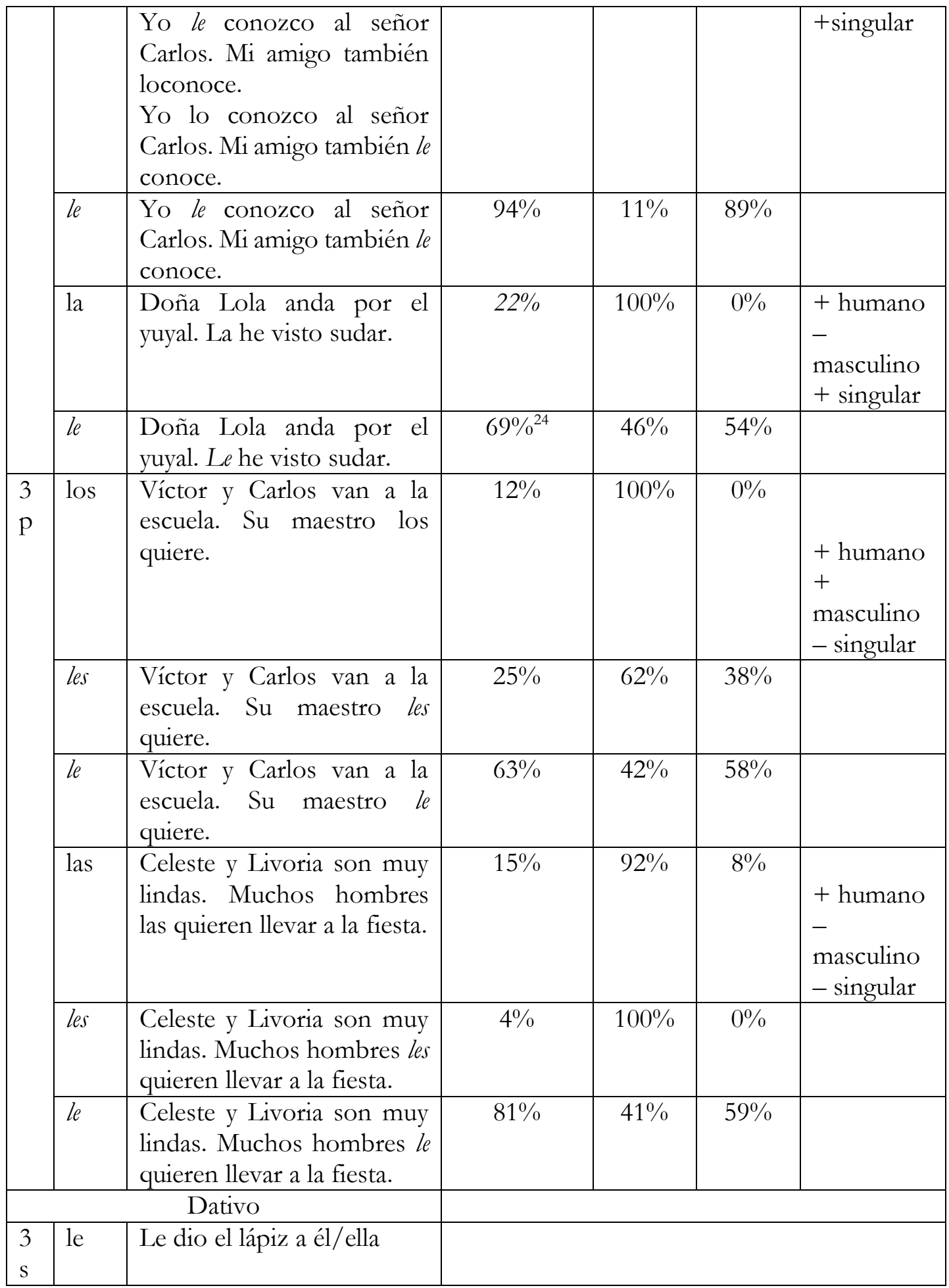

${ }^{24}$ Debe tratarse de un error porque $69+22=91 \ldots$ 


\section{\begin{tabular}{|l|l|l|}
\hline 3 & le & Le dio el lápiz a ellos/ellas \\
$\mathrm{p}$ & &
\end{tabular}}

El corpus de Symeonidis (2013) pertenece al Atlas lingüístico Guaraní-Románico ${ }^{25}$ (THUN, 2002), del que refiere haber participado directamente en la recolección de los datos. Aclara que para su investigación utilizó 86 entrevistas de informantes de Asunción, Tacumbú, Paraguarí, Caazapá, Alto Paraná, San Pedro, Amambay, Concepción y Alto Paraguay, divididos en dos clases sociales en función del grado de escolarización: clase baja (Cb), con hasta cuatro años de escolarización, y clase alta (Ca), con entre 5 y 8 años de escolarización, y en dos grupos etarios: (GI) de 18 a 36 años y (GII) de más de 50 años. Refiere también que para examinar las interferencias en el uso de los pronombres en posición de objeto directo se dio a los informantes una serie de frases guaraníes para que fueran traducidas al español y que para el artículo en cuestión utiliza exclusivamente las de referente (+ humano).

\section{EL FENÓMENO DEL LEÍSMO}

El español cuenta con dos series paralelas de pronombres de complemento u objeto directo e indirecto, una átona o clítica y otra tónica. Los pronombres átonos o clíticos del español de primera y segunda persona derivan del acusativo latino, los pronombres tónicos, del nominativo y del dativo latino, mientras que los pronombres de tercera persona derivan del demostrativo latino: los átonos del acusativo y dativo y los tónicos del nominativo, como se puede apreciar en la Tabla 1. La serie tónica del plural, que no posee formas diferenciadas del nominativo, se construye en español anteponiendo la preposición a como única marca explícita de función gramatical. Los pronombres tónicos de objeto como los sintagmas nominales de objeto indirecto van siempre precedidos por la preposición $a$. Los pronombres tónicos se refieren siempre a persona, y su presencia no es obligatoria, lo que implica necesariamente la presencia de uno de los pronombres átonos.

A lo largo de la historia del español es muy común la confusión y/o alternancia entre dativo y acusativo, así como la diferente valoración del fenómeno por parte de la comunidad lingüística hispanohablante a lo largo de los siglos. Se pueden encontrar incluso numerosos fenómenos de leísmo en escritores pertenecientes a zonas distinguidoras del caso, como señala Cuervo (1895), debido a la influencia ejercida por el peso normativo de determinados centros culturales sobre la forma de escribir, donde la inclinación por le como clítico de acusativo referido a antecedentes masculinos parece muchas veces depender de preferencias estilísticas y personales. A partir del siglo XIX, y en contraste con lo que sucedía entre los siglo XVI y XVIII, se da una notable reducción del uso de le acusativo, sin duda por el peso normativo de la RAE que a partir de 1854

25 Zimmermann (2015) refiere que para el atlas fueron escogidos solamente informantes bilingües, que en el cuestionario se consideraron la variación dialingual, diatópica, diastrática, diageneracional, diasexual, diafásica y diareferencial y que se limita a dos clases sociales, alta y baja, según el nivel de escolaridad, y a dos grupos etarios. 
introduce un cambio radical en relación al pronombre de acusativo masculino, imponiendo el uso exclusivo de lo en lugar de le, que hasta entonces había sido la única forma tolerada. Como refiere Fernández Ordoñez (1999) tal cambio ocurrió por influencia de Salvá (1988), que lo introdujo en su gramática de 1830, y luego de Bello (1995), que lo introdujo en la suya de 1847, postura que se ha mantenido hasta el Esbozo de una nueva gramática de la lengua española, RAE (1973). La Nueva gramática de la lengua española, RAE (2009), que se define panhispánica, describe y acepta el uso de le en acusativo masculino singular de persona además de describir y tolerar otras formas de leísmo como pertenecientes a usos cultos y estándar en diferentes variedades del español peninsular y americano.

El fenómeno del leísmo se viene explicando desde el siglo XIX por Salvá (1988), en 1830, y Cuervo (1895), y en el siglo XX por Fernández Ramírez (1964, 1987) desde 1951, Lapesa (2000) desde 1968 y Marcos Marín (1978), entre otros, desde dos diferentes hipótesis que actuarían conjunta y contradictoriamente:

a) La primera hipótesis, la etimológica, explica el uso pronominal átono de zonas distinguidoras y confundidoras en parte como resultado de la prolongación de usos latinos, como refiere Fernández Ordoñez (1999):

El leísmo para objetos directos masculinos en el singular (tanto de persona como de cosa), el laísmo y el loísmo (con referente neutro o masculino plural) tendrían su origen en la tendencia a crear en castellano un paradigma de los pronombres átonos basado en el de los demostrativos (este-a-o, estos-as), en el que se eliminarían las distinciones de caso a favor de las de género: le-la-lo, los-las. La distinción acusativo/dativo dejaría de ser pertinente en los pronombres de tercera persona, igual que no lo es en los de primera y segunda (donde me, te, nos, os refieren tanto a antecedentes en posición sintáctica de objeto directo como de objeto indirecto). (FERNÁNDEZ ORDOÑEZ, 1999, p. 1321)

b) La segunda hipótesis explica el fenómeno por la tendencia del castellano a distinguir entre entes personales y no personales.

Según Fernández Ordoñez (1999), ninguna de estas hipótesis explica la totalidad de los fenómenos encontrados en los datos manejados por estos autores, además de que dichos datos proceden exclusivamente de la lengua escrita culta, por lo que no serían representativos del fenómeno:

La principal objeción proviene de su incapacidad predictiva: el leísmo en sus diferentes tipos, el laísmo y el loísmo se juzgan como fenómenos de variación porcentual sobre el total de ejemplos observados, sin que pueda predecirse qué produce su aparición en cada caso salvo las tendencias mencionadas ni se aclare el porqué de la mayor frecuencia de unas confusiones frente a otras. Ello tiene su origen en no haber contemplado la posibilidad de que existieran diferencias dialectales entre las distintas áreas confundidoras del mundo hispanohablante y en haber manejado la misma y única hipótesis para todas ellas. [...] Al agrupar en el estudio estadístico los ejemplos sin segregarlos según la procedencia de los hablantes de una u otra zona confundidora, se distorsionan los datos. (FERNÁNDEZ ORDOÑEZ, 1999, p. 13211322) 
Fernández Ordoñez (1999) refiere que la tendencia de muchos autores de finales del siglo XX es trabajar a partir del análisis de la lengua hablada elaborando diferentes interpretaciones del fenómeno relacionadas directamente con el área geográfica investigada en cuestión, y que gracias a estudios sociolingüísticos se comprobó además la necesidad de diferenciar el habla culta del habla popular en cada zona estudiada, ya que el habla culta estaría siempre bastante próxima al sistema distinguidor de caso mientras que el habla popular es la que representaría al sistema autóctono de cada zona. Por estos motivos Fernández Ordoñez (1999) recomienda que se deban distinguir en la interpretación de los datos tres situaciones diferentes:

1) el leísmo de las zonas que distinguen el caso pronominal,

2) el leísmo de las zonas donde el español convive con lenguas no-indoeuropeas,

3) el leísmo en los lugares en que está acompañado por laísmo y loísmo.

\section{EL FENÓMENO DEL LEÍSMO EN PARAGUAY}

En Paraguay han convivido y conviven históricamente el español y el guaraní desde la conquista hasta el presente. La hipótesis que la gran mayoría de los autores ha utilizado para explicar el fenómeno del leísmo en el español paraguayo ha sido la de la influencia de la lengua indígena de sustrato, en este caso el guaraní.

Según Herreros (1976) la causa del leísmo en el español paraguayo es la interferencia sobre el sistema pronominal personal átono de tercera persona de la forma guaraní ichupe y su correspondiente plural ichupekuéra, que en guaraní funcionan como objeto directo e indirecto pronominal personal de tercera persona. Para Herreros (1976) la invariabilidad en guaraní de ichupe / ichupekuéra ha podido determinar, por un proceso de interferencia, el empleo de las formas le y les como pronombres de objeto directo e indirecto, de modo paralelo al guaraní, originándose así el actual leísmo del español paraguayo.

Granda (1982) rechaza dicha hipótesis como factor causal primario por razones que considera internas o estructurales y por razones externas. Considera que la atribución primaria del influjo guaraní sobre el leísmo paraguayo choca con la existencia de otras áreas hispanoamericanas en las que existe igualmente leísmo y en las que no se habla guaraní y que por lo tanto han debido actuar otros factores causales en la producción del fenómeno, lo que no quita que, en el caso concreto de Paraguay, la interferencia del guaraní también haya participado en la formación del leísmo local. Critica también que Herreros (1976) considere que el leísmo paraguayo derive de un proceso evolutivo que haya llevado al sistema pronominal personal átono de tercera persona del castellano a calcar el del guaraní, compuesto solamente por dos elementos morfológicos, el singular ichupe y el plural ichupekuéra, utilizados tanto para referirse a objeto directo como a indirecto. Sostiene que Herreros (1976), quizá influenciada por Kany (1969), cree que en Paraguay, al igual que en Ecuador, se utilicen los dos morfemas le y les,y, basándose en este dato, haya deducido que en esta dualidad reproduce la dualidad paralela existente en guaraní ichupe / ichupekuéra. Granda (1982) sostiene que esto no ocurre ya que, salvo en los casos derivados de la presión de la enseñanza escolar o del prestigio de las normas 
rioplatense o peninsular europea, el leísmo del español paraguayo está representado por un sólo morfema pronominal átono le, utilizado tanto para el singular como para el plural, con lo que no se produce el paralelismo pretendido por Herreros (1976) entre los paradigmas del español paraguayo y del guaraní, y que de este modo desaparece la posibilidad de que haya sido la interferencia del guaraní sobre el español local la causante primaria del fenómeno.

La hipótesis de Granda (1982), que define como de causación múltiple y que coincide con la hipótesis de Fontanella de Weinberg (1993) en relación a la importancia de los actores y procesos históricos involucrados en la génesis de las diferentes variedades, es que las causas genéticas del fenómeno se encuentran: a) ya sea en la base dialectal peninsular europea del español que llegó a Paraguay de la mano de los conquistadores, como en b) la interferencia del guaraní paraguayo coloquial o jopará y del guaraní clásico, c) la simplificación periférica, d) el resultado de la convivencia de sistemas lingüísticos en contacto y, finalmente, e) la actuación secular de tendencias internas dentro de los paradigmas morfosintácticos del español colonial de Hispanoamérica.

Granda (1982) sostiene la presencia de leísmo en el español de los primeros núcleos europeos fundadores de agrupaciones urbanas en Paraguay, leísmo similar al que, en los siglos XV y XVI, se manifestaba en las áreas norteñas peninsulares, y que hubiera sido perfectamente posible que los primeros conquistadores y colonizadores lo hubiesen transportado consigo dentro de los rasgos lingüísticos del español originario. Sostiene además que tanto en la expedición de Pedro de Mendoza en 1535 como en las posteriores, de Cabeza de Vaca en 1543, de Diego de Sanabria en 1547 y de Ortiz de Zárate en 1571, que constituyeron en conjunto el aporte humano básico de origen europeo a la población de la Gobernación del Paraguay durante los siglos XVI y XVII, se encontraban conquistadores y colonizadores de origen vasco y castellano norteño, en especial burgaleses, todos de áreas leístas, según datos recopilados por Machaín (1937).

En relación a la interferencia del guaraní paraguayo coloquial o jopará, que es hablado por la población mestiza bilingüe, Granda (1982) refiere que presenta varios prestamos del español, como por ejemplo los morfemas la y lo,que son utilizados como artículos singular y plural, respectivamente, y también, en el caso de la, como equivalente a: lo que, la que, los que, las que, que y a diferentes locuciones adverbiales. Por lo que sugiere que, en el uso del español, hayan seleccionado las formas le/les, que se encontraban "vacantes" en el paradigma guaraní, con preferencia a lo y la, como pronombre átono de objeto directo de tercera persona, para evitar ambigüedad funcional y semántica entre ambas lenguas.

En cuanto a la simplificación periférica y a las interferencias de sistemas coloca como ejemplo la desmorfologización de la forma les en le por el principio de economía morfológica y la tendencia fonética hacia la debilitación o eliminación de $s$ final en el área paraguaya, reforzada por la estructura fonética de la sílaba guaraní que sólo admite como elemento implosivo postnuclear la consonante nasal.

Palacios (2000) refiere que el guaraní carece de un sistema pronominal personal átono de tercera persona por lo que no tiene equivalentes para los pronombres de dativo y de acusativo del español, y que la construcción pronominal guaraní exige la presencia de 
un pronombre tónico de tercera persona en un sintagma preposicional tal que no admite diferencia formal entre la función de objeto directo y objeto indirecto, como se puede ver en las siguientes oraciones (PALACIOS, 2000, p. 137):

Che sy o-becha-kuri ichu-pe

Mi madre 3s-ver-pasado él-a (Mi madre _ vio a él) lo

Che sy o-me'ëjopói ichu-pe

Mi madre 3s-dar regalo él-a (Mi madre _ da regalo a él) le

Refiere además que el guaraní no tiene marcas gramaticales de género entre los pronombres, ya que el género no está gramaticalizado, y que el plural de tercera persona se crea agregando kuéra al sintagma preposicional ichu-pe: ichupekuéra, pero que en la práctica habitual de la lengua hablada, tampoco hay gramaticalización de número.

Palacios (2000) sostiene que el leísmo americano se explique por el contacto de lenguas, a diferencia del leísmo peninsular, que afecta a la neutralización del rasgo de caso en favor de la potenciación del rasgo de género, y que simplifica por medio de los siguientes ejemplos: "Le vi a Pedro / La vi a María / Le di un regalo a Pedro / La di un regalo a María” (PALACIOS, 2000, p. 125-126), de donde deduce que le y la funcionan como objeto directo e indirecto sin que la función sintáctica (caso) sea relevante y que la elección del pronombre dependa del género del referente. Palacios (2000) sostiene que las tres características del sistema pronominal paraguayo: leísmo, loísmo y elisión de objeto son producto del contacto del guaraní con el español, que se corresponden con el concepto de convergencia lingüística, y que se deba "a las características estructurales de las lenguas amerindias que permiten, activan y fomentan la aparición de un sistema pronominal distinto al resto de las modalidades del español" (PALACIOS, 2000, p. 133), como sostiene que ocurre en las demás zonas americanas de contacto de lenguas, como Ecuador y la sierra Peruana en el caso del quechua y las zonas de contacto con el mapuche, según retoma de Kany (1969). Sostiene que ambos fenómenos, el leísmo y el loísmo del español paraguayo, sean el resultado de un proceso de reestructuración del sistema pronominal español que, en cuanto al loísmo, consiste en la neutralización de los rasgos de género y número, y en cuanto al leísmo, en la neutralización de los rasgos de género, número y caso, lo que supone la invariabilidad pronominal hacia una forma única le o lo. Palacios (2000, p. 140-141) sostiene entonces que: "En definitiva, estamos ante un caso de convergencia lingüística de las estructuras morfosintácticas pronominales del guaraní y del español y no ante un caso de calco sintáctico", y que por este motivo no debería hablarse de "leísmo" del español paraguayo y si de "tendencia hacia la invariabilidad pronominal, que puede aparecer como le, pero también como 10 ”.

Sin embargo, nosotros consideramos que haya ciertas contradicciones en la argumentación de Palacios (2000), además de una interpretación ligeramente tendenciosa de los datos en función de su propia hipótesis ya que, según sus datos, aparecen muchos casos de utilización del pronombre átono lo completamente encuadrados en el marco de 
la norma estándar y que incluye dentro de los casos de loísmo, como por ejemplo, en Palacios (2000, p. 130-131):

"La familia a lo mejor prepara un serdito o un serdo para marlo en Navidad"

"Un trabajo de diezpersonas, se van a bacerlo"

"Llevan bebida de todo, se emborrachan bien, hasta que lo gaste todo [el dinerio]"

"Todo el mundo tiene melón y si no tiene, pues te lo da la dueña fulana, la vesinita te manda de regalo"

"Lo vah a ver variah, variah mujere" 26

Y los incluye porque simplemente define al loísmo como: "entendido como la pronominalización de objetos mediante la forma lo, como única forma pronominal sin que los rasgos de género o número sean relevantes" (PALACIOS, 2000, p. 128-129), metiendo en la misma bolsa a los casos que respetan la utilización estándar.

Además de esto, no podemos olvidar que los fenómenos de leísmo, loísmo y de elisión del pronombre átono de tercera persona están presentes tanto en las variedades del español peninsular europeo como en otras variedades americanas, por lo que no es correcto concluir, como concluye Palacios (2000, p. 124), que "son producto del contacto del guaraní con el español” cuando en realidad lo que sí se podría hipotetizar que sucedió, desde nuestro punto de vista, es que las características intrínsecas del guaraní hayan potenciado dichos fenómenos en el español paraguayo.

Más allá de estas observaciones, lo interesante en los datos de Palacios (2000) es la relevancia del uso de otros pronombres de tercera persona, independientemente de que sean casos de loísmo o no, ya que esto significa que la situación del sistema pronominal de complementos de tercera persona en el español paraguayo no se restringe exclusivamente al uso del pronombre le, como indican Herreros (1976) y Granda (1982).

Symeonidis (2013) adhiere a la hipótesis de la influencia del guaraní sobre el español paraguayo pero sin dar demasiadas explicaciones a no ser por el hecho de que el guaraní no posee marcas gramaticales para diferenciar el género de los pronombres tónicos en función de objeto. Refiere que las características del leísmo del español paraguayo son: a) la elisión del pronombre de tercera persona cuando el referente es inanimado y b) el uso generalizado del leísmo cuando el referente es animado. Refiere que en guaraní no hay pronombres átonos para la función de objeto que se diferencien de los tónicos y que por lo tanto no hay como referenciar objetos inanimados, que no hay diferencia formal entre el objeto pronominal en función de objeto directo e indirecto ya que el sistema pronominal de objeto del guaraní no discrimina las funciones sintácticas de objeto directo e indirecto.

\section{SITUACIÓN SÓCIO-HISTÓRICA DE PARAGUAY}

Según Granda (1982), Paraguay, además de ser un país bilingüe por excelencia, atravesó una situación histórico-político-económica única en América. Sostiene que el

${ }^{26}$ Esta frase es ambigua de todas formas. 
Paraguay fue condenado al aislamiento periférico ya desde el inicio de la conquista tras una serie de frustradas expediciones que llevaron a la Corona Española a convencerse de que allí no existían riquezas, y que los pobladores, abandonados por la metrópoli, prácticamente incomunicados con el Alto Perú, de cuya Audiencia de Charcas dependían, lejos de la costa atlántica y de sus puertos, debieron limitarse a una ganadería escasamente productiva y a una agricultura de mera subsistencia hasta el siglo XVII, con el auge de la yerba mate. Y que todo esto, sumado a la continua situación de guarnición fronteriza continuamente amenazada por los indios chaqueños por el Oeste y por las incursiones de los portugueses por el Este, produjo una situación de pobreza general que se mantuvo hasta finales del siglo XVIII, tras la apertura oficial al tráfico marítimo del puerto de Buenos Aires, la diversificación de cultivos y la desaparición de la competencia para el cultivo de yerba mate, lo que mejoró claramente la situación económica del Paraguay. Refiere que sólo superaría su situación de extremo subdesarrollo en la breve etapa de gobierno de Carlos Antonio López, 1844-1862, y de su hijo el Mariscal Francisco Solano López, 1862-1870, pero que la Grande Guerra de 1865-1870 lo volvería a sumir en la pobreza. Granda (1982) refiere que la educación suministrada en Paraguay se limitaba al nivel primario y a las escasas enseñanzas de las casas religiosas de la Provincia, y que era tan mediocre que "[...] en 1625 y en 1753, por ejemplo, el Cabildo de Asunción tuvo que dirigirse al Rey exponiendo el peligro de que los hijos de los conquistadores adquirieran las costumbres de los indios y solicitando en vano, la fundación de un colegio en la capital de la Provincia" (GRANDA, 1982, p. 276) y que en 1650 y 1678 el Cabildo Catedral informó oficialmente que los sacerdotes ordenados por el Obispo Cárdenas apenas sabían leer. Refiere que en 1700 sólo tres paraguayos contaban con el título de Doctor debido a la pobreza y a la gran distancia entre Asunción y Córdoba o Chuquisaca, sedes de las Universidades más cercanas, y que sólo en 1783 se inauguró en Asunción el Real Colegio Seminario de San Carlos, que fue suprimido en 1822 por órdenes del Doctor Francia, por lo que Paraguay no tendría otros centros de enseñanza media y superior hasta el gobierno de Carlos Antonio López.

Por todas estas cuestiones y por el hecho de haberse desarrollado en un aislamiento total prácticamente hasta el siglo XIX -lo que lo llevó a que fuera denominado el Tíbet de América-, y por la falta del peso normativo de un centro cultural, Paraguay alcanzó una prácticamente nula estandarización lingüística que según Fontanella de Weinberg (1993) llevó a los hablantes a una relajación por ausencia de modelos de prestigio lingüístico.

Granda (1982) coloca así a Paraguay en la categoría de área periférica tanto en el ámbito socio histórico como lingüístico, y propone la hipótesis de la causación múltiple para explicar el particular fenómeno del leísmo del español paraguayo, lo que está en línea con la hipótesis de Fontanella de Weinberg (1993): una serie de diferentes factores actuando en conjunto y configurando una serie determinada de características, ya que, por más que la interferencia de la lengua indígena de sustrato tenga un peso tan significativo por tratarse de una realidad única de bilingüismo sostenido en el tiempo, dicha interferencia no excluye otros factores como el peso demográfico y social de los actores involucrados en un proceso secular de interacciones, sobre todo considerando que por casi dos siglos no se verificó en Paraguay la llegada de nuevos contingentes de 
colonizadores españoles, lo que produjo, en el caso del leísmo paraguayo, la persistencia del fenómeno específico desde el siglo XVI hasta finales del siglo XVIII.

\section{SITUACIÓN LINGÜÍSTICA DEL PARAGUAY}

Paraguay es una nación bilingüe en la que en la actualidad ambas lenguas, el guaraní y el español, tienen el mismo estatus y son enseñadas obligatoriamente en todos los niveles educativos.

Kallfell (2016) refiere que cuando los españoles llegaron a Paraguay al mando de Juan de Ayolas, quien ordenó a Juan de Salazar de Espinoza la fundación del fuerte de la Asunción a orillas del río Paraguay en 1537, los indios guaraníes no opusieron ninguna resistencia por considerarlos semidioses y ver en ellos a un buen aliado contra las tribus vecinas. Refiere que entonces los guaraníes les dieron tierras y mujeres en abundancia con la idea de emparentarse, tanto que el contaba con cinco o seis, mientras había quien llegaba incluso a setenta mujeres. De allí nació la prole de los llamados mancebos de la tierra, mestizos bilingües que hablaban un español limitado sobre todo a lo concerniente a la administración y a lo militar y que constituyó la base del español paraguayo actual. Así se desarrolló poco a poco una sociedad constituida en su mayor parte por mestizos, de cuya élite participaban los que podían enorgullecerse de su ascendencia hispánica, lo que produjo que el prestigio del español creciera enormemente y asegurara así su supervivencia. Desde entonces, las dos lenguas, el español (karai ñe'ẽ 'lengua de los señores') y el guaraní (ava ñe' 'e 'lengua de los indios'), fueron inseparables y mutuamente relacionadas. Refiere también que hubo interferencias tanto del guaraní al español como a la inversa, y que aunque la mayoría hablaba el ava ñe'ẽ, lengua tribal hoy desaparecida por su alto grado de hispanización, el influjo del español en la lengua autóctona fue mucho mayor por vía de los mancebos de la tierra, que, como capa más influyente de la población, se familiarizaron con ambas lenguas e introdujeron inconscientemente nuevos elementos en la lengua indígena que se extendieron después también a los hablantes monolingües.

Granda (1982) refiere la coexistencia en Paraguay del guaraní tribal, del guaraní clásico o misionero, hablado por los indios guaraníes, en donde no se dan hispanismos, del español y del jopará: el guaraní paraguayo coloquial actual, hablado por la población mestiza y que presenta varios prestamos del español, como hemos visto.

Palacios (2003) sostiene que la situación lingüística de Paraguay se caracteriza por la coexistencia de dos lenguas alejadas genética y estructuralmente: el guaraní, lengua indoamericana, y el español, lengua románica. Y que dicha convivencia ha permitido que el español paraguayo se vea influenciado por el guaraní a nivel lexical, morfosintáctico y sintáctico y que las consecuencias inmediatas se reflejan en la variación de ciertas estructuras lingüísticas del español por influencia del guaraní, con tal incidencia que:

[...] se puede afirmar que algunas de estas variantes locales han sido elevadas al rango de norma y son empleadas como español estándar por los distintos estratos poblacionales. Así, esa norma local se ha superpuesto y sustituido a lo que entendemos como norma estándar culta. (PALACIOS, 2003, p. 808) 
Y sostiene incluso que dichas variantes son socialmente prestigiosas y que podemos encontrarlas en diferentes ámbitos desde el coloquial, al universitario o hasta en los medios de comunicación e incluso en la lengua escrita.

Kallfell (2016) refiere que hoy en día más de la mitad de los paraguayos son bilingües y que casi el $90 \%$ de la población paraguaya hablan en mayor o menor grado el guaraní, el que, sobre todo en las zonas rurales, es con frecuencia el único medio de comunicación. Refiere que después de casi quinientos años de bilingüismo con un permanente influjo recíproco se ha alcanzado:

[...] una convergencia lingüística duradera en esa situación llamada de interestrato. Se ha constituido así, por una parte, el español paraguayo con sus características, y por otra, el guaraní hablado, que en todos sus campos lingüísticos presenta fuertes interferencias con el español o bien con la permanente presencia de ambas lenguas. Como resultado nos encontramos con un "hablar con dos lenguas", que los paraguayos en su lengua autóctona llaman jopara $(<j \mathrm{o}-$ pará 'penetración recíproca' = 'mezcla'). A esto se contrapone el guaraniete (<guaraní + eté [gwaranie' te] 'verdadero/puro' guaranî), que hoy solamente se presenta en la lengua escrita. (KALLFELL, 2016, p. 9)

\section{CONSIDERACIONES FINALES}

Consideramos que el fenómeno del leísmo del español paraguayo no se trate exclusivamente ni de un caso de calco de estructuras sintácticas del guaraní sobre el español como propuso Herreros (1976), ni de un caso de contacto de lenguas por convergencia lingüística que se deba exclusivamente "a las características estructurales de las lenguas amerindias que permiten, activan y fomentan la aparición de un sistema pronominal distinto al resto de las modalidades del español" por neutralización de los rasgos de género, número y caso como propuso Palacios (2000, p. 133).

Como sugieren Granda (1982) y Fontanella de Weinberg (1993), no se debe atribuir el fenómeno a una única causa si se tiene en cuenta que:

a) el fenómeno del leísmo ya estaba presente en las variedades peninsulares de los españoles que poblaron lo que fue y es hoy el territorio Paraguayo;

b) las características estructurales del guaraní;

c) la aislación periférica que vivió Paraguay por casi tres siglos y que derivó en una muy baja estandarización que produjo un fenómeno de innovación de realización de estructuras intensamente simplificadas.

De todas formas, de los datos de Herreros (1976), Granda (1982), Palacios (2000) y Symeonidis (2013) se puede ya entrever un desplazamiento de le como única forma pronominal hacia una alternancia cada vez mayor con lo,además de una mínima pero cada vez más significativa presencia de la y las, sobre todo en los sociolectos más altos y con mayor grado de escolarización.

Nuestra hipótesis es que muy probablemente el español paraguayo irá a sufrir todavía más variaciones hacia el lado de la norma, impelidas por el peso normativo de los 
diferentes polos culturales, fenómenoque sólo futuras investigaciones podrá confirmar o refutar.

\section{REFERENCIAS}

APPLEYARD, José Luís de. Los monólogos. Asunción: Colección Oñondivepa, 1973.

BELLO, Andrés. Gramática de la lengua castellana destinada al uso de los americanos, [1847]. In: BELLO, Andrés. Edición digital a partir de obras completas. v. 4, $3^{\mathrm{a}}$ ed. Caracas: La Casa de Bello, 1995.

CUERVO, Rufino José. Los casos enclíticos y proclíticos del pronombre de tercera persona en castellano. Romania, [S.L.], v. 24, n. 93-94, p. 95-113, p. 219-263, 1895.

FERNÁNDEZ ORDOÑEZ, Inés. Leísmo, laísmo y loísmo. In: REAL ACADEMIA ESPAÑOLA. Gramática descriptiva de la lengua española. v. 2, $1^{\mathrm{a}}$ ed. Madrid: Espasa Calpe, 1999, p. 1317-1397.

FERNÁNDEZ RAMÍREZ, Salvador. Un proceso lingüístico en marcha. In: I Congreso de Instituciones Hispánicas, 1964, Madrid. Presente y futuro de la lengua española. Madrid: OFINES, 1964, p. 277-285, v. 2.

. El pronombre, [1951]. In: POLO, José (Ed.). Gramática española. $1^{\mathrm{a}}$ ed. Madrid: Arco/Libros, 1987, p. 40-55.

FONTANELLA DE WEINBERG, María Beatriz. El español de América. $2^{a}$ ed. Madrid: Mapfre, 1993.

GRANDA, Germán de. Origen y formación del leísmo en el español del Paraguay. RFE, [S.L.], v. 74, n.3, p. 259-283,1982.

HERREROS, Beatriz Usher de. Castellano paraguayo. Notas para una gramática contrastiva castellano-guaraní. Suplemento Antropológico,v. 11, n. 1/2, Asunción,p. 29-123, 1976.

KALLFELL, Guido. ¿Cómo hablan los paraguayos con dos lenguas? Gramática del Jopara. 2016. 311 f. Tese. (Doutorado). Westfälischen Wilhelms, Universität zu Münster, Münster. Disponível em: [http://www.etnolinguistica.org/biblio:kallfell-2016-jopara]. Acesso em: 7 fev. 2018.

KANY, Charles Emil. Sintaxis hispanoamericana. $1^{\text {a }}$ ed. Madrid: Gredos, 1969.

LAPESA, Rafael. Sobre los orígenes y evolución del leísmo, laísmo y loísmo, [1968]. In: LAPESA, Rafael. Estudios de morfosintaxis histórica del español. v. 1, 1ª ed. Madrid: Gredos, 2000, p. 279-310.

MACHAÍN, Ricardo de Lafuente. Conquistadores del Rio de la Plata. $1^{\mathrm{a}}$ ed. Buenos Aires: [s.n.], 1937.

MARCOS MARÍN, Francisco. Estudios sobre el pronombre. 1a ed. Madrid: Gredos, 1978.

PALACIOS, Azucena. El sistema pronominal del español paraguayo: un caso de contacto de lenguas. In: CALVO, Julio (Ed.). Teoría y práctica del contacto de lenguas en América: el español en el candelero. $1^{\mathrm{a}}$ ed. Madrid-Frankfurt: Iberoamericana-Vervuert, 2000, p. 123143. 


\section{Revista

. Acerca del contacto de lenguas: español y guaraní. In: I Simposio Internacional sobre o Bilingüismo, 1997, Vigo. Comunidades e individuos bilingües. Vigo: Servicio de Publicacións da Universidade de Vigo, 2003, p. 807-817.

REAL ACADEMIA ESPAÑOLA. Esbozo de una nueva gramática de la lengua española. $1^{\mathrm{a}} \mathrm{ed}$. Madrid: Espasa Calpe S.A., 1973.

. Gramática descriptiva de la lengua española. $1^{a}$ ed. Madrid: Espasa Calpe, 1999.

- ASOCIACIÓN DE ACADEMIAS DE LA LENGUA ESPAÑOLA. Nueva gramática de la lengua española. $1^{\text {a }}$ ed. Madrid: Espasa Libros, 2009.

ROA BASTOS, Augusto. Hijo de hombre. Madrid: Alfaguara, 1989.

SALVÁ, Vicente. Gramática de la lengua castellana según abora se habla [1830]. $1^{a}$ ed. Madrid: Arco Libros, 1988, 2 v.

SYMEONIDIS, Haralambos. Análisis sociolingüístico del leísmo en el español paraguayo. Revista Internacional d'Humanitats, Barcelona: Univ. Autònoma de Barcelona Dep. de Ciències de l'Antiguitat i de l'Edat Mitjana, año 16, n. 27, p. 55- 68, ene-abr 2013. THUN, Harald (Ed.). Atlas lingüistico guarani-románico. $1^{a}$ ed. Kiel: Westensee-Verlag, 2002, v 2 (Sociología: ALGR-S).

ZIMMERMANN, Klaus. A integração geolinguística através do atlas lingüístico guaranírománico. Revista Pbilologus. Rio de Janeiro: CiFEFiL, 21, n. 63, p. 166-170, 2015.

Recebido em: 28/02/2019

Aprovado em: 07/06/2019

Publicado em: 28/09/2019 